\title{
Polyunsaturated fatty acid relatively decreases cholesterol content in THP-1 macrophage-derived foam cell: partly correlates with expression profile of CIDE and PAT members
}

Yue Song ${ }^{1,3+}$, Li-Jun Zhang ${ }^{2 \dagger}$, Hang Li ${ }^{1,4 \dagger}$, Yu Gu${ }^{1}$, Fan-Fan Li ${ }^{1}, \mathrm{Li}-\mathrm{Na}$ Jiang ${ }^{1}$, Fang Liu'${ }^{1}$, Jing Ye ${ }^{1 *}$ and Qing Li ${ }^{1 *}$

\begin{abstract}
Background: Polyunsaturated fatty acids (PUFAs) have positive effect on the regulation of plasma lipids. But the mechanism for them to modulate lipid homeostasis in macrophage is still unclear. In this study, we employed PUFA to pretreat macrophages and evaluated the variations of lipid droplet (LD) content, lipid composition, and expressions of LD-associated genes in macrophage-derived foam cells.
\end{abstract}

Method: THP-1-derived macrophages or human peripheral blood monocyte-derived macrophages were pre-treated with four non-esterified fatty acids (NEFAs) separately: saturated fatty acid (SFA)-palmitic acid (PA), monounsaturated fatty acids (MUFAs)-oleic acid (OA), PUFAs-linoleic acid (LA) and eicosapentaenoic acid (EPA). Intracellular lipid content and cholesterol efflux were analyzed in THP-1 macrophage-derived foam cells. Related gene expressions were detected by quantitative real-time PCR.

Results: PUFA pre-treatment reduced cholesterol content in foam cells and increased cholesterol efflux to lipid-free apoAl in conditioned medium compared with PA or OA group. Cell death-inducing DFF45 like effector (CIDE) and Perilipin-Adipophilin-TIP47 (PAT) family members, as LD-associated proteins, showed specific gene expression profiles after PUFA pre-treatment. These results may help to explain the process of lipid metabolism within foam cells.

Conclusion: PUFA (LA or EPA) had a potential protective effect against cholesterol accumulation. The specific expressions of CIDE and PAT genes may provide clues to explore the protective mechanism of PUFA in foam cells.

Keywords: Polyunsaturated fatty acid, CIDE, PAT, Lipid metabolism, Atherosclerosis

\section{Background}

PUFAs are essential components in lipid metabolism. It has been reported that PUFAs can affect lipid storage and reduce the risk factors of cardiovascular diseases [1]. However, the potential role of PUFA in the formation of fatty streak and atherosclerotic plaque is not yet clear. The molecular mechanism for PUFA-induced lipid influx and efflux in foam cells is inconclusive.

Abnormal lipid deposition in the intima of artery wall leads to the formation of fatty streak. Macrophages take-

\footnotetext{
* Correspondence: yejing@fmmu.edu.cn; liqing@fmmu.edu.cn

${ }^{\dagger}$ Equal contributors

'State Key Laboratory of Cancer Biology and Department of Pathology, Xijing Hospital, Fourth Military Medical University, Xi'an, China

Full list of author information is available at the end of the article
}

up the oxidized LDL (ox-LDL), stores a large portion of lipids in their cytoplasm, and turn into foam cells [2,3]. The formation, morphology and lipolysis of intracellular LDs are regulated by a number of LD-associated proteins [4]. These proteins are located on the surface of LDs and play active roles in the regulation of intracellular lipid storage, nascent LD biogenesis and transportation [5-8]. CIDE and PAT proteins are by far the most specific LD-associated proteins being found. Proteomic analyses also confirmed that the most abundant proteins in LDs were the CIDE and PAT family members [9]. The peroxisome proliferator-activated receptor $\gamma($ PPAR $\gamma)$ is considered as an important transcription factor involved in the regulation of gene expression of most of LDassociated proteins [10-12]. Microarray analysis in our

\section{() BioMed Central}


previous study [8] showed that CIDE and PAT members, together with PPAR $\gamma$ regulated proteins, had meaningful expression changes in the process of THP-1 macrophagederived foam cells formation. These data suggested that CIDE or PAT proteins were closely related to intracellular LD formation. But different NEFA-induced protein expressions are still not clear.

In this study, THP-1-derived macrophages and peripheral blood monocyte-derived macrophages were pretreated separately with PA, OA, LA and EPA (difference in saturation). We intend to simulate a microenvironment of monocyte-derived macrophages in artery wall. The lipid composition of intracellular LDs was identified by quantitative analysis in two cell groups separately. By analyzing cholesterol efflux and mRNA expression profiles of CIDE, PAT and PPARy transcriptional regulatory proteins in THP-1 macrophage-derived foam cells, we try to present a potential relationship among PUFA pre-treatment, lipid loading and LD-associated gene expression.

\section{Results}

Identification of the optimum incubation condition

Before the experiment, we examined the cytotoxicity of employed fatty acids on THP-1 macrophages with MTT assay. NEFA pre-treatment increased cell death rate in a time- and dose-dependent manner (Figure 1). Compared with the control group, 48 hours' incubation by each NEFA had no effect on macrophage viability. While after 72 hours' incubation, there were at least $75 \%$ cells survived in each group, which is sufficient for the following experiments. Concentration of NEFAs can also affect macrophage viability. Cell survival rate decreased slightly

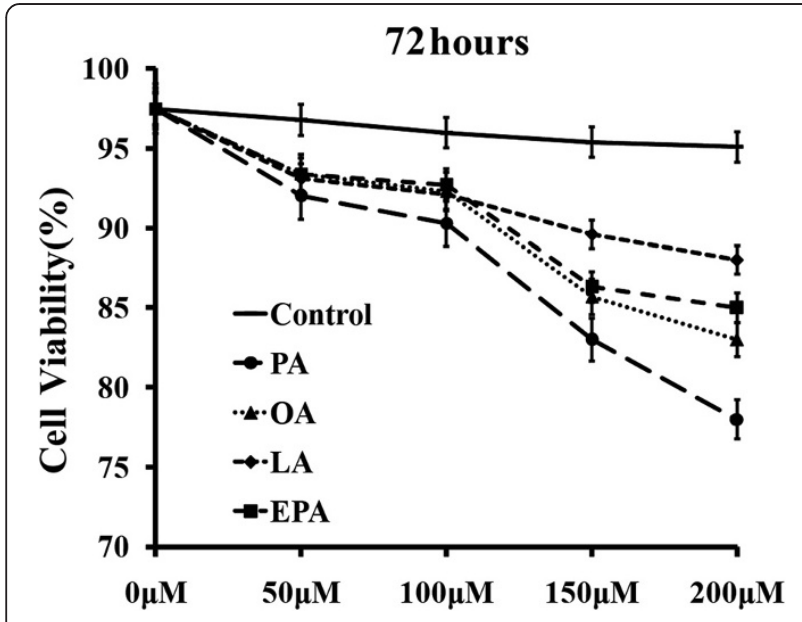

Figure 1 Cell viability of THP-1 macrophage after pre-treatment with different NEFAs at different concentrations for $\mathbf{7 2}$ hours. The THP-1-derived macrophages were pretreated by PA, OA, LA and EPA separately with time and dose gradients. The cell viability was determined by MTT colorimetric assay. Data represent mean \pm $\operatorname{SEM}(n=3)$. after 72 hours pre-treatment with $100 \mu \mathrm{M}$ NEFAs. However, when the concentration was elevated to $200 \mu \mathrm{M}$, all the NEFAs markedly decreased cell viability $(P<0.05$ separately). Therefore, we chose $100 \mu \mathrm{M}$ and 72 hours as the optimum concentration and time condition for macrophages incubation in the following study.

\section{PUFA induced relatively lower lipid content in foam cells}

THP-1-derived macrophages were separately exposed to different NEFAs in advance for 72 hours. Then ox-LDL was added to facilitate the formation of foam cells. Intracellular LDs were stained with Nile Red (Figure 2A). And the LD content was quantified by measuring the positive area in macrophages and foam cells (Figure 2B). Due to the intake of ox-LDL, foam cells in the control group contained more LDs compared with non-ox-LDL treated THP-1 macrophages. All the four NEFAs could efficiently increase the total area of LDs in foam cells compared with control $(P<0.05)$. Lipid content in PUFA group was lower than that in PA and OA group $(P<0.05)$. To verify the effect of pre-treatment of PUFA, we then incubated human peripheral blood monocyte-derived macrophages with different NEFAs separately. The quantitative analysis of lipid content in foam cells was consistent with that in THP-1 macrophage-derived foam cells (Figure 2A-B). These findings illustrated that, compared with PA and OA, PUFAs (LA and EPA) could cause relatively less lipid content during foam cells formation.

\section{PUFA relatively inhibited cholesterol accumulation in foam cells}

We measured intracellular TG, TC and CE levels in both THP-1 macrophage- and monocyte macrophage-derived foam cells. Each NEFA could elevate the level of TG compared with respective control $(P<0.05$, Figure 3A). PUFA induced less accumulation of TC and $\mathrm{CE}$ than PA or OA did during the process of foam cell formation $(P<0.05$ respectively, Figure $3 \mathrm{~B}-\mathrm{C}$ ). These results indicated that the lower lipid content in PUFA pre-treated group was partly due to less cholesterol accumulation.

\section{PUFA increased cholesterol efflux to lipid-free apoAI in conditioned medium}

To test whether the lower intracellular cholesterol accumulation was caused, at least partly, by increased cholesterol efflux, we performed cholesterol efflux assays. We detected the amount of cholesterol efflux from THP-1 macrophage-derived foam cells to either lipidfree apoAI or to HDL in medium. There was no statistical significance in cholesterol efflux to HDL among NEFA groups. But cholesterol efflux to lipid-free apoAI was markedly increased in PUFAs (LA and EPA) groups compared with that in PA or OA group (Figure 4). 


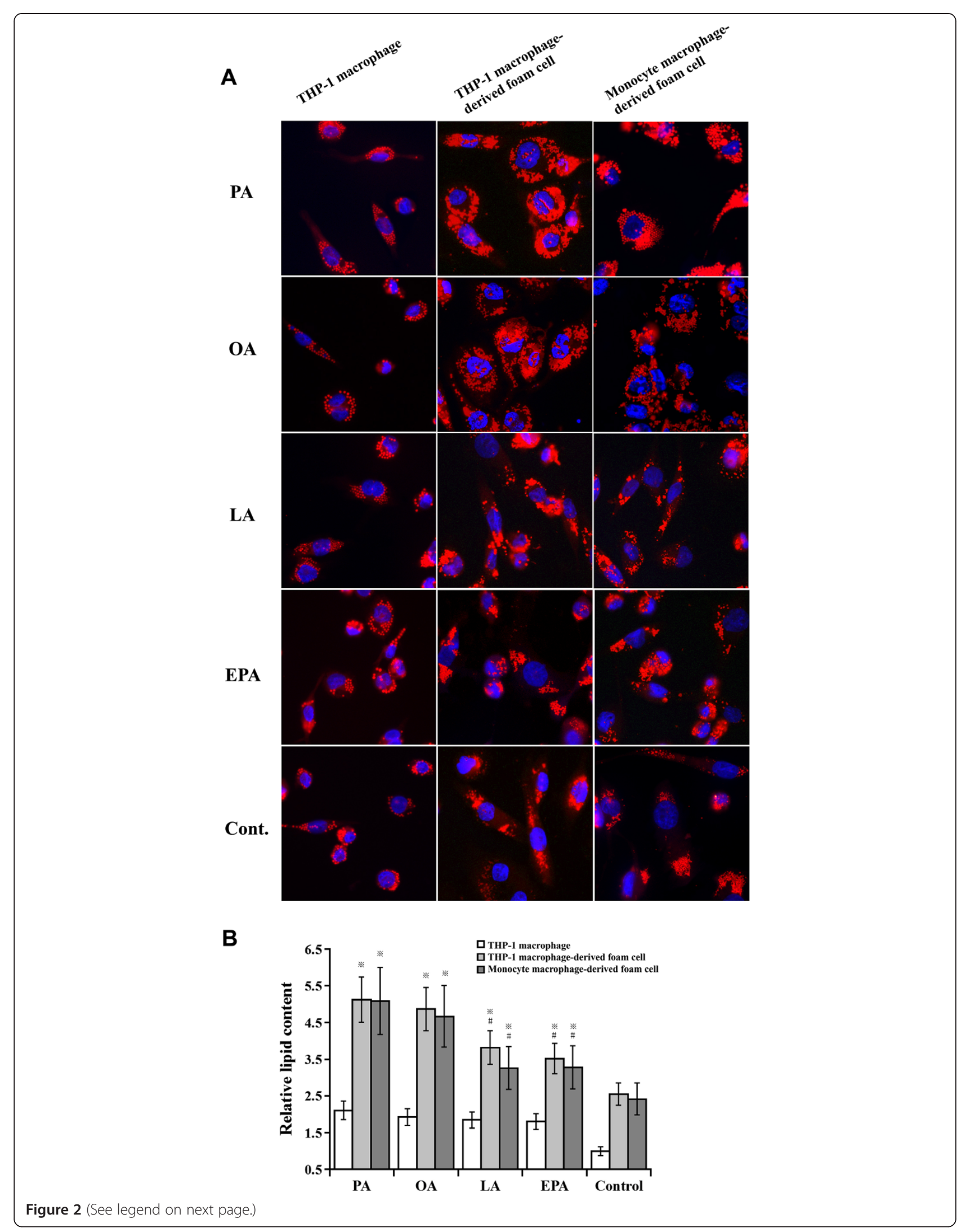


(See figure on previous page.)

Figure 2 Effects of PUFAs on intracellular lipid accumulation. Both THP-1 macrophages and monocyte macrophage were pre-treated with different NEFA at the concentration of $100 \mu \mathrm{M}$ for 72 hours. Then ox-LDL was added to facilitate foam cell formation. The intracellular lipid droplets were stained with Nile Red (A). The average positive area of stained LDs per cell was used to quantify the intracellular lipid content (B). Data represent mean \pm SEM $(n=3) .{ }^{*} p<0.05$ vs. control; ${ }^{*} P<0.05$ vs. PA/OA group.

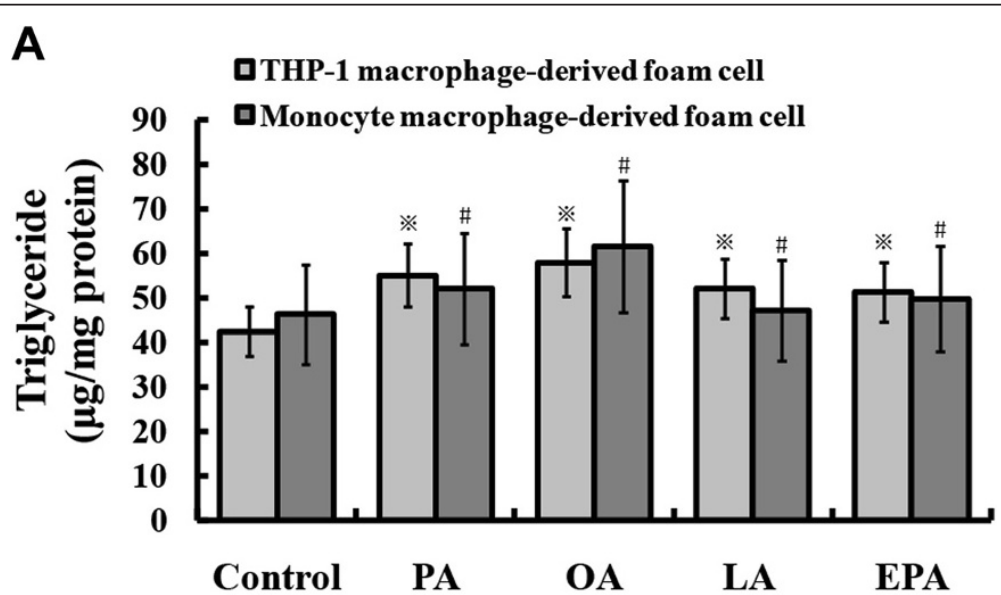

B
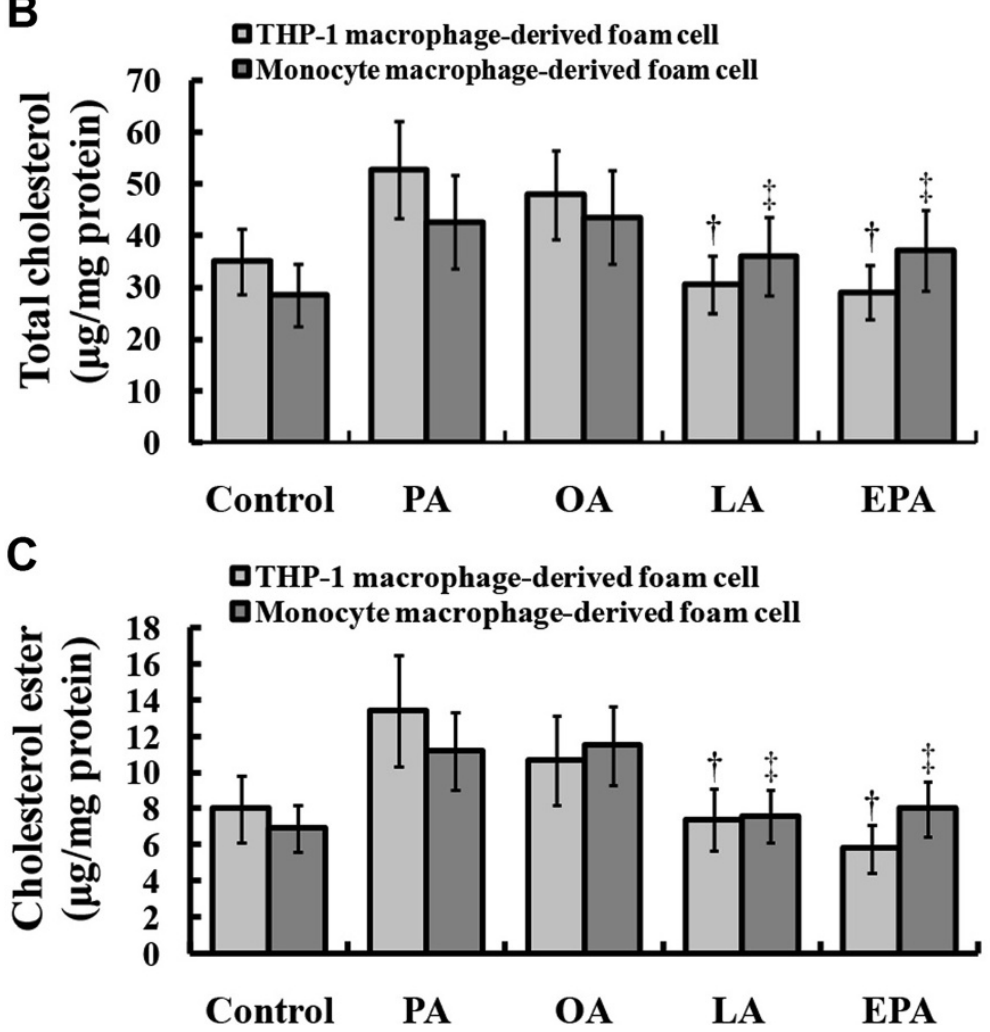

Figure 3 Quantitative determination of TG, TC and CE in foam cells. The THP-1 macrophages or monocyte macrophages were pre-treated with different NEFA in advance, and then ox-LDL was added to facilitate foam cell formation. Intracellular TG, TC and free cholesterol were determined by enzymatic colorimetric assays (A-B). The concentration of CE was determined by subtracting free cholesterol from TC (C). Data represent mean $\pm \operatorname{SEM}(n=3) .{ }^{* / \#} P<0.05$ vs. control $(\mathbf{A}){ }^{\dagger / \neq} P<0.05$ vs. PA/OA group (B-C). 


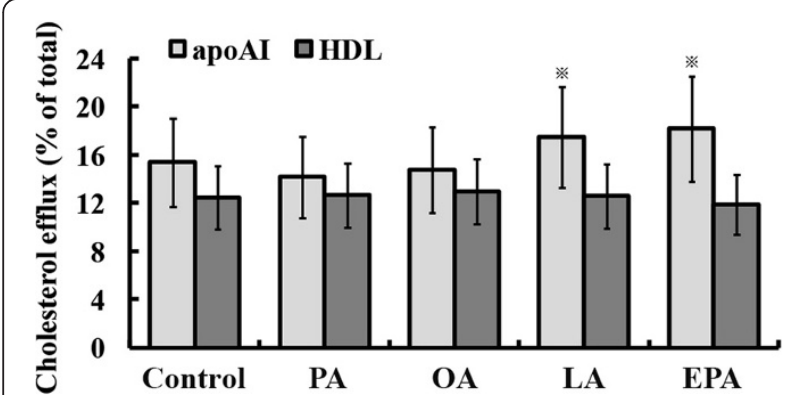

Figure 4 Effects of PUFAs on cholesterol efflux to lipid-free apoAl or to HDL. THP-1 macrophages or monocyte-macrophages were pre-treated with different NEFA, and then incubated with ox-LDL containing $1 \mu \mathrm{Ci} / \mathrm{ml}[3 \mathrm{H}]$ cholesterol and $2 \mathrm{mg} / \mathrm{ml} \mathrm{BSA}$. The

radioactivity was measured by scintillation counting. Cholesterol efflux to apoAl from foam cells was increased in LA and EPA groups. PUFAs had no effect on cholesterol efflux to HDL from foam cells. Data represent mean \pm SEM $(n=3) .{ }^{*} p<0.05$ vs. control.

The mRNA levels of PPARy transcriptional regulated proteins were closely correlated with intracellular lipid content

PPAR $\gamma$ is a critical nuclear receptor regulating the expression of LD-associated proteins [6], part of which have been found having specific expression profiles during foam cell formation [8,12]. In our previous microarray analysis, we found that the expression of SRA1, CD36, ABCA1 and apoAI showed interesting changes. In this study, we tried to clarify potential roles of these genes in modulating cellular lipid loading after PUFA pre-treatment. Data in Figure 5 and Table 1 directly showed fold-changes of related mRNAs in foam cells vs. in macrophages. Specific NEFA induced mRNA expression on macrophages and foam cells were shown in Additional file 1: Figure S1 and Additional file 2: Figure S2.

PPAR $\gamma$ can be activated by some long-chain saturated or unsaturated fatty acids. We found that PUFA separately decreased the expression of SR-A1 and CD36, while increased the expression of apoAI in foam cells compared with PA or OA. PUFA also induced notable fold-increase of apoAI compared with the untreated foam cell control. ABCA1 was markedly up-regulated by EPA but not by LA. The expression profiles of PPAR $\gamma$ related proteins induced by PUFAs were, to a great extent, consistent with lower cholesterol accumulation and higher cholesterol efflux. SFA and MUFA neither showed protective effect against lipid loading nor induced similar expressions of related genes as PUFAs in foam cells.

\section{Expression profiles of CIDE and PAT members were correlated with PUFAs induced LD formation}

Our previous study has shown that LD-associated proteins have specific expression profiles in the process of foam cell formation. In this study, we further investigate NEFA-induced alterations of CIDE and PAT members in foam cells.

As shown in Figure 6A and Table 1, PUFA significantly up-regulated the expression of Cidea and Cidec while reduced the expression of Cideb compared with the foam cell control. PAT family members have been proved to be the dominant LD-associated proteins. NEFA-induced foldchanges of PAT members in transcriptional level were showed in Figure 6B and Table 1. ADRP, a protein which has similar function with Perilipin, increased remarkably

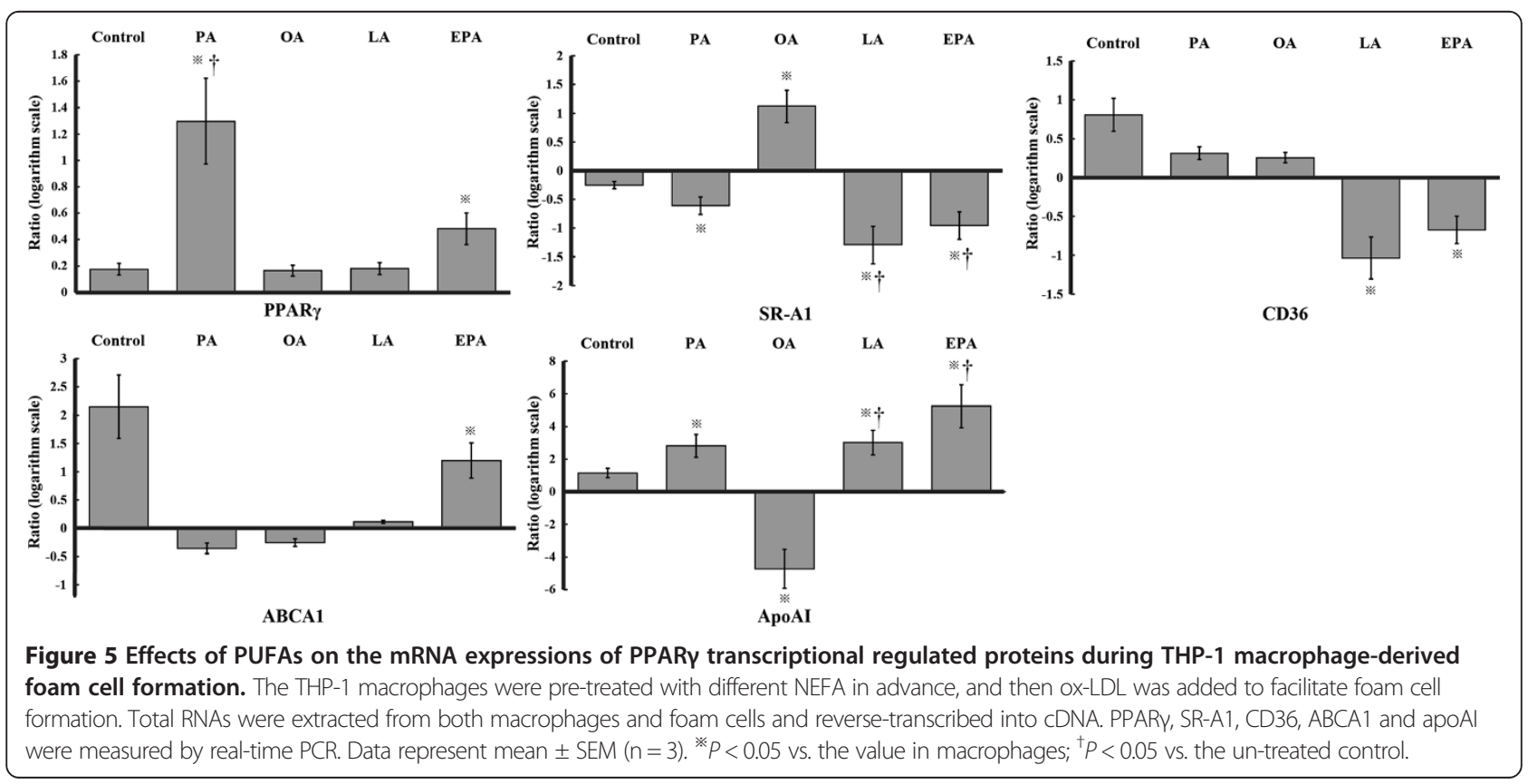


Table 1 Specific NEFA induced fold-changes of mRNAs

\begin{tabular}{llllll}
\hline Protein & Control & PA & OA & LA & EPA \\
\hline SR-A1 & -0.25 & $-0.61^{*}$ & $1.12^{*}$ & $-1.30^{* \#}$ & $-0.96^{* \#}$ \\
CD36 & 0.81 & 0.32 & 0.26 & $-1.03^{*}$ & $-0.67^{*}$ \\
ABCA1 & 2.15 & -0.36 & -0.26 & 0.11 & $1.20^{*}$ \\
ApoAl & 1.15 & $2.82^{*}$ & $-4.73^{*}$ & $3.02^{* \#}$ & $5.24^{* \#}$ \\
PPARy & 0.18 & $1.30^{* \#}$ & 0.17 & 0.18 & $0.48^{*}$ \\
Cidea & 0.02 & $-1.54^{*}$ & $-3.87^{*}$ & $3.17^{* \#}$ & $1.02^{\#}$ \\
Cideb & 1.35 & $2.43^{*}$ & $1.67^{*}$ & $0.28^{\#}$ & $0.17^{\#}$ \\
Cidec & 0.65 & -0.24 & -0.27 & $0.84^{\#}$ & $1.75^{* \#}$ \\
Perilipin & -0.15 & $-2.11^{*}$ & $-3.04^{*}$ & $2.42^{*}$ & -0.24 \\
ADRP & 4.05 & $5.22^{*}$ & $4.36^{*}$ & $9.55^{* \#}$ & $7.78^{* \#}$ \\
TIP47 & 0.99 & $1.39^{*}$ & $0.54^{*}$ & $-1.79^{*}$ & $2.04^{* \#}$ \\
S3-12 & 0.38 & $2.10^{*}$ & $-2.80^{*}$ & $6.30^{* \#}$ & $3.21^{* \#}$ \\
LSDP5 & 1.03 & $1.60^{*}$ & $-2.02^{*}$ & $2.96^{* \#}$ & 0.10 \\
\hline Valles we & & & &
\end{tabular}

Values were presented as: $\log _{2}$ (mRNA level in foam cell/mRNA level in macrophage).

$\left({ }^{*} P<0.05 ;{ }^{*} P<0.05\right.$ vs. respective control). by each NEFA pre-treatment. ADRP showed greater foldincrease in PUFA groups compared with it in PA or OA group. Interestingly, of all employed NEFAs, LA induced the highest fold-increase of PAT members except for TIP47, and EPA similarly induced significantly foldincrease of PAT members except for Perilipin. These specific gene expression profiles, combined with their functions in the process of LD formation, provided a relevant explanation to the alterations of intracellular lipid content.

\section{Discussion}

Numerous studies show that PUFAs play potential roles in maintaining serum lipid homeostasis. Population-based study found that high level of fish intake was good for cardiovascular health [13]. PUFA had been reported to be a protective agent against atherosclerosis (AS) [14,15]. In this study, we chose different NEFAs according to their importance in human diet. NEFAs are rich in meat (PA), plant fats (OA, LA), and fish oils (EPA $n-3)$. PA (16:0), OA (18:1 n-9), and LA(18:2n-6) are the most abundant fatty acids in fatty streaks of human [16]. Our study confirmed that compared with SFA and MUFA, PUFAs (LA and

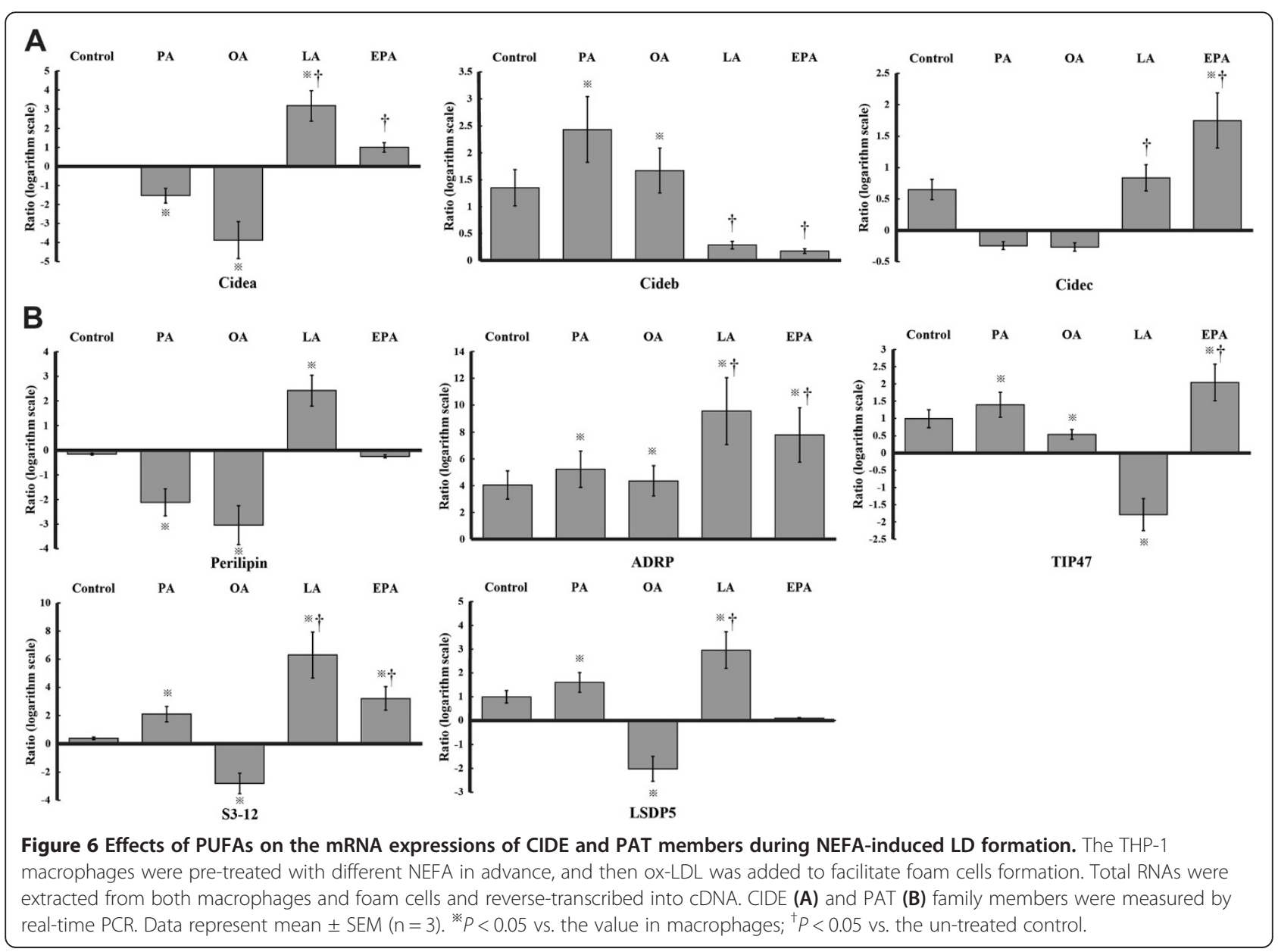


EPA) could relatively reduce intracellular TC and CE, thus lower the total lipid content in foam cells. However, NEFAs were stored as TGs in budding LDs and ox-LDL lipids were added to the pre-existing ones, which increased sizes of LDs finally. This helps to explain the theory that PUFA promotes the storage of TG.

NEFAs regulate gene expressions by acting directly or indirectly as ligands for nuclear acceptors [17]. PPAR $\gamma$ binds DNA in the form of heterodimer with retinoid $\mathrm{X}$ receptor (RXR) and maintains lipid homeostasis in macrophages by regulating the expression of scavenger receptors including SR-A1 and CD36 [5]. Meanwhile, PPAR $\gamma$ is the upstream regulator of ATP-binding cassette transporter ABCA1 and apolipoprotein AI (apoAI). The classic pathway of cholesterol efflux from macrophages is that CD36 or SR-A1 on the surface of macrophages recognizes and engulfs ox-LDL, and then ABCA1 exports cholesterol and phospholipids to lipid-free apoAI, forming small $\mathrm{HDL}$ particles [6]. In this study, EPA or LA significantly reduced the gene expression of SR-A1 and CD36, and EPA further increased the expression of ABCA1. These alterations corporately contributed to the less cholesterol uptake and more cholesterol efflux. Though lipid-poor apoAI is not synthesized by macrophages, we found PUFAs could upregulate the mRNA level of apoAI. It is worth noting that the higher expression of apoAI increased cholesterol efflux in macrophages [18]. The protective effects of apoAI can also be attributed to its anti-inflammatory and antioxidative properties, not directly related to plasma HDL cholesterol levels [19]. NEFA-induced lipid accumulation in foam cells may be caused by increased lipid influx mediated by CD36. The up-regulation of ABCA1 was accompanied by the increased cholesterol efflux to apoAI and the reduced intracellular lipid content. These findings suggested that ABCA1 played a key role in regulating intracellular lipid accumulation. The ABCA1 appears to be the most effective receptor in mediating cholesterol efflux to apoAI. The half transporter ABCG1 also, to some extent, facilitates cholesterol efflux to HDL as acceptor [20-22]. The elevated cholesterol efflux to apoAI in medium rather than to HDL in EPA group supported the finding that EPA may induce more cholesterol efflux through ABCA1 pathway. But the lower fold-increase of ABCA1 in LA group indicated that there might be other pathways participating in the modulation of cholesterol efflux. But the changes of ABCA1 and ABCG1 in protein level have not been investigated in our experiment. Further study in this area is needed.

CIDE family consists of Cidea, Cideb and Cidec/Cide3. They play important roles in lipid storage, LD formation and lipolysis [23]. But their expression profiles and functions in AS is still unclear. Cidea protein, surrounding LDs and co-localizing with Perilipin, can efficiently repress lipolysis in human adipocytes [24,25]. Cidec inhibits lipolysis, promotes TG accumulation and contributes to the stability of formed LDs $[8,13,24]$. Fold-increase of Cidea and Cidec in PUFAs pre-treated foam cells may be helpful to promote TG accumulation and inhibit lipolysis $[3,26]$. Thus PUFA may exert its protective role by reducing the lipotoxicity in foam cells. Our previous study showed that the down-regulation of Cideb was closely related to the enhanced hepatic fatty acid oxidation [27]. It is certain that Cideb plays an important role in affecting lipid metabolism in foam cells, though whether Cideb could enhance lipid oxidation or lipolysis still needs further investigation.

PAT family is composed of five members: Perilipin, ADRP, TIP47, S3-12 and LSDP5. Perilipin and ADRP are constitutive proteins on LD membranes [28,29]. ADRP participates in LD formation in macrophages and foam cells [30] and facilitates cholesterol efflux from macrophages [31]. The increased ADRP and Perilipin in PUFA pre-treated group may help to reduce the toxicity of NEFA and contributes to the synthesis of lipid (including TG). Nascent LDs are predominantly decorated by TIP47 and S3-12 [17]. As lipid droplet coats, these two proteins are interchangeable and are necessary for TG storage [5,30]. LSDP5 is a PPAR $\gamma$-induced LD-associated protein which can promote the fatty acid positioning. The expression of LSDP5 is also associated with the increased TG accumulation, for it can promote expansion of the storage pool of lipid substrates [28,32]. In conclusion, PUFAs have positive effect on maintaining TG content, reducing TC and CE contents in LDs. These effects may be closely related to the separate or combined expression of CIDE and PAT members. The meaningful alterations of these LD-associated proteins in mRNA level may provide us new ideas to explore lipid metabolism in foam cells.

Although PUFAs could not completely resist lipid deposition in foam cells, it can effectively reduce the accumulation of cholesterol. Several factors related to lipid metabolism in foam cells have been observed in this study, but the cause-effect studies have not been thoroughly conducted and further investigation is needed.

This study addressed that PUFAs pre-treated macrophage-derived foam cells showed dynamic gene changes. The expression of PPAR $\gamma$ and LD-associated proteins in transcriptional level can be, at least in part, linked to the process of LD formation. In summary, the different effects of NEFAs on TG and cholesterol flux in foam cells depend on an integrated function of relevant genes. We believe that the gene expression profiles of CIDE and PAT members should also be used as important indicators of LD metabolism in foam cells. More detailed researches should be performed in future to clarify the mechanism of lipid accumulation in foam cells. 


\section{Materials and methods Materials}

Human monocytic leukemia THP-1 cells were kindly donated by Dr. Bo-quan Jin (Department of Immunology, Fourth Military Medical University, Shaanxi, China). Human buffy coats were purchased from blood bank of Xijing Hospital (Fourth Military Medical University, Shaanxi, China). Whole human HDL (density $=1.063$ 1.021, containing $\mathrm{HDL}_{2}$ and $\mathrm{HDL}_{3}$ ) was purchased from Union Medical College (Beijing, China). Unless otherwise specified, all other reagents were purchased from Sigma-Aldrich (Shanghai, China).

\section{Monocyte isolation}

A two-step procedure was used to isolate monocyte from buffy coats. Firstly, peripheral blood mononuclear cells (PBMCs) were isolated from buffy coats using a Ficoll-Hypaque gradient (density $=1.070$ ). Then a slight hyperosmolar Percoll gradient (density $=1.064$ ) was used for monocyte isolation [33]. Percoll solutions were prepared as follows: first an isosmotic Percoll was prepared by mixing one volume $\mathrm{NaCl} 1.5 \mathrm{M}$ with nine volumes of Percoll (density $=1.130$ ). Then the Percoll gradient was done by mixing isosmotic Percoll with PBS/Citrate $\left(\mathrm{NaH}_{2} \mathrm{PO}_{4} 1.49 \mathrm{mM} ; \mathrm{Na}_{2} \mathrm{HPO}_{4} 9.15 \mathrm{mM}\right.$; $\mathrm{NaCl} 139.97 \mathrm{mM} ; \mathrm{C}_{6} \mathrm{H}_{5} \mathrm{Na}_{3} \mathrm{O}_{7} .2 \mathrm{H}_{2} \mathrm{O} 13 \mathrm{mM}$; pH 7.2) in a 1: 1 (v/ v) ratio. Both gradients were centrifuged at 25$35^{\circ} \mathrm{C}, 400 \mathrm{~g}$ for $35 \mathrm{~min}$. The purity of monocytes after the Percoll gradient isolation was higher than $85 \%$. Platelets were eliminated by low speed centrifugation $(100 \mathrm{~g})$ after the Percoll gradient isolation.

\section{Cell culture}

THP-1 cells and human peripheral monocytes were cultured in RPMI-1640 medium (Gibco, US) supplemented with 10\% fetal bovine serum (FBS, Gibco, US), penicillin $(100 \mathrm{U} / \mathrm{ml})$ and streptomycin $(100 \mu \mathrm{g} / \mathrm{ml})$ in $\mathrm{CO}_{2} / \mathrm{O}_{2}$ incubator at $37^{\circ} \mathrm{C}$. Then cells were incubated with $100 \mathrm{ng} / \mathrm{ml}$ phorbol 12-myristate 13-acetate (PMA) for 24 hours to facilitate macrophage formation. The adherent macrophages were washed three times with phosphate-buffered saline (PBS) and incubated with cell culture medium containing 2\% FBS for another 24 hours with or without NEFA. After the incubation, macrophages were treated with $50 \mu \mathrm{g} / \mathrm{ml}$ ox-LDL for another 48 hours for foam cell formation.

\section{Toxicology assay}

The THP-1-derived macrophages were treated by different NEFAs separately with time and dose gradients. The cell viability was tested using 3-(4,5-Dimethylthiazol-2yl)-2,5-diphenyltetrazolium bromide (MTT) colorimetric assay as previously described [34]. THP-1 macrophages were separately cultured with NEFAs in a final concentration from $50 \mu \mathrm{M}$ to $200 \mu \mathrm{M}$ in 96-well micro plates for 24 hours to 96 hours. After an appropriate incubation $\left(37^{\circ} \mathrm{C}, 4\right.$ hours with $20 \mu \mathrm{l} \mathrm{MTT}(5 \mathrm{mg} / \mathrm{ml})$ in each well), $150 \mu \mathrm{l}$ dimethyl sulfoxide (DMSO) was used to replace the medium containing MTT, and then plates were shook for 10 minutes. Absorbance at $490 \mathrm{~nm}$ was measured. Each experiment was independently repeated three times. Bovine serum albumin (BSA) mixed with DMSO and PBS was set as the control.

\section{Isolation and oxidation of LDL}

Native LDL (density=1.020-1.063) were isolated from human plasma by sequential flotation ultracentrifugation at $60,000 \mathrm{rpm}\left(24\right.$ hours, $\left.10^{\circ} \mathrm{C}\right)$. Before oxidative modification, the LDL was dialyzed against PBS, filtered through a $0.2 \mu \mathrm{m}$ millipore membrane and stored in PBS containing $10 \mathrm{mM}$ EDTA at $4^{\circ} \mathrm{C}$. LDL oxidation was induced by

Table 2 Real-time PCR primer sequences

\begin{tabular}{|c|c|c|}
\hline Gene & Primer sequences & $\begin{array}{l}\text { Genebank } \\
\text { number }\end{array}$ \\
\hline \multirow[t]{2}{*}{$S R-A 1$} & Forward: CCAGGGACATGGGAATGCAA & NM_138715.2 \\
\hline & Reverse: CCAGTGGGACCTCGATCTCC & \\
\hline \multirow[t]{2}{*}{ CD36 } & Forward: GAGAACTGTTATGGGGCTAT & NM_001001548.2 \\
\hline & Reverse: TTCAACTGGAGAGGCAAAGG & \\
\hline \multirow[t]{2}{*}{$A B C A 1$} & Forward: GCACTGAGGAAGATGCTGAAA & NM_005502.2 \\
\hline & Reverse: AGTTCCTGGAAGGTCTT GTTC & \\
\hline \multirow[t]{2}{*}{ ApoAl } & Forward: TGTGTCCCAGTTTGAAGGC & NM_000039.1 \\
\hline & Reverse: CTCCTITTCCAGGTTATCCCAG & \\
\hline \multirow[t]{2}{*}{ PPARY } & Forward: CACAAGAACAGATCCAGTGGTTGCAG & NM_005037.5 \\
\hline & Reverse: AATAATAAGGTGGAGATGCAGGCTCC & \\
\hline \multirow[t]{2}{*}{ Cidea } & Forward: GGGATCACAGACTAAGCGAG & NM_001279.3 \\
\hline & Reverse: TGACGAGGGCATCCAGAG & \\
\hline \multirow[t]{2}{*}{ Cideb } & Forward: TGATGGTGTTGCAGTCTGG & NM_014430.2 \\
\hline & Reverse: AAAGAGGTCTCGAGGGTTTG & \\
\hline \multirow[t]{2}{*}{ Cidec } & Forward: TTGATGTGGCCCGTGTAACGTTG & NM_022094.2 \\
\hline & Reverse: AAGCTTCCTTCATGATGCGCTTGG & \\
\hline \multirow[t]{2}{*}{ Perilipin } & Forward: GCCATGTCCCTATCAGATGC & NM_001145311.1 \\
\hline & Reverse: GTTGTCGATGTCCCGGAATT & \\
\hline \multirow[t]{2}{*}{$A D R P$} & Forward: CTGAGCACATCGAGTCACATACTCT & NM_001122.2 \\
\hline & Reverse: GGAGCGTCTGGCATGTAGTGT & \\
\hline \multirow[t]{2}{*}{ TIP47 } & Forward: GCTGGACAAGTTGGAGGAGA & NM_001164189.1 \\
\hline & Reverse: CCGACACCTTAGACGACACA & \\
\hline \multirow[t]{2}{*}{$53-12$} & Forward: ACATCTTCCACCCCATGAATG & NM_001080400.1 \\
\hline & Reverse: GTGTTCAAATGCCCGCTG & \\
\hline \multirow[t]{2}{*}{ LSDP5 } & Forward: AGCACGATGTCTGAAGAAGAG & DQ_839131.1 \\
\hline & Reverse: TCCTTGGCTGCACTGTAAAC & \\
\hline \multirow[t]{2}{*}{ HPRT1 } & Forward: TGACACTGGCAAAACAATGCA & NM_005502.2 \\
\hline & Reverse: GGTCCTTTTCACCAGCAAGCT & \\
\hline
\end{tabular}


$40 \mathrm{mM} \mathrm{HOCl}$ (corresponding to oxidant/protein molar ratios of 2000/1) for $30 \mathrm{~min}$ at $37^{\circ} \mathrm{C}$. Ox-LDL was dialyzed overnight against saline $(0.15 \mathrm{M} \mathrm{NaCl}$ and $300 \mu \mathrm{M}$ EDTA, $\mathrm{pH}$ 7.4). The protein concentration was determined by methods of Lowry [35].

\section{NEFA pre-treatment}

Macrophages were exposed to NEFAs at a final concentration of $100 \mu \mathrm{M}$ which was within the physiologic plasma range [32,36]. After 24 hours incubation, $50 \mu \mathrm{g} / \mathrm{ml}$ ox-LDL was added. Macrophages were incubated for another 48 hours to induce foam cells formation. Each NEFA was conjugated by fatty acid free BSA in a 4:1 molar ratio at $37^{\circ} \mathrm{C}$ for at least 1 hour prior to treatment as previously described [37]. NEFA was added to the culture medium with a minimal volume $(<0.1 \%)$ of DMSO. Three independent experiments with triplicate samples (each sample with $2.5 \times 10^{6}$ cells $/ 60 \mathrm{~mm}$ dish) were performed for each test.

\section{Cholesterol loading and efflux}

After treatment with PMA and NEFA, THP-1 macrophage were washed with PBS and incubated with $50 \mu \mathrm{g} / \mathrm{ml}$ ox-LDL, $1 \mu \mathrm{Ci} / \mathrm{ml}\left[{ }^{3} \mathrm{H}\right]$ cholesterol and $2 \mathrm{mg} / \mathrm{ml} \mathrm{BSA} \mathrm{for}$ 40 hours. After $8 \mathrm{~h}$ equilibration with MEM containing $1 \mathrm{mg} / \mathrm{ml}$ of BSA, macrophages were washed twice with PBS and treated for $12 \mathrm{~h}$ with serum-free medium containing: (1).2 mg/ml BSA; (2).2 mg/ml BSA and $15 \mu \mathrm{g} / \mathrm{ml}$ lipid-free human apoAI; (3).2 mg/ml BSA and $50 \mu \mathrm{g} / \mathrm{ml}$ of human HDL. Then the supernatant was collected and centrifuged at $12000 \mathrm{rpm}$ for $15 \mathrm{~min}$ to remove debris. Cells were lysed with $0.5 \mathrm{ml}$ of $0.1 \mathrm{~N}$ $\mathrm{NaOH}$. The radioactivity in both the supernatant and cellular lipid was measured by scintillation counting. Background efflux was determined by control cells incubated with $2 \mathrm{mg} / \mathrm{ml}$ BSA. Human HDL was prepared as previously described [38,39]. The data were normalized by total $\left[{ }^{3} \mathrm{H}\right]$-cholesterol radioactivity in supernatant and cell pellet.

\section{Real time quantitative PCR assay}

The targeted genes, primer sequences and Genebank number for real-time PCR assays performed in this study are summarized in Table 2. Total RNA was extracted from macrophages and foam cells (THP-1 cell line) with Trizol reagent (Invitrogen, US) and then reverse transcribed to cDNA in a final volume of $30 \mu \mathrm{l}$. Real-time PCR assays were performed with an iCycler IQ Real Time PCR Detection System (BIO-RAD,US) and the SYBR Prime Script RT-PCR Kit (Takara Dalian, China). 5 pmol primer and $100 \mathrm{ng}$ CDNA were used in a final volume of $25 \mu \mathrm{l}$. Homo sapiens hypoxanthine phosphoribosyl transferase 1 (HPRT1) was used as a housekeeping gene for its stable expression in monocytes and macrophages. The
PCR amplification program was $95^{\circ} \mathrm{C}$ for 3 minutes, followed by 45 cycles of $95^{\circ} \mathrm{C}$ for 30 seconds (s), $60^{\circ} \mathrm{C}$ for $30 \mathrm{~s}$ and $72^{\circ} \mathrm{C}$ for $30 \mathrm{~s}$. All samples were tested three times.

\section{Lipid analysis}

Cells were fixed in 4\% paraformaldehyde for 30 minutes, and then washed three times with PBS before incubated in a working solution of Nile Red. Nucleus of the cell was dyed with Hoechst 33258 as previously described [8]. The image of lipid staining was captured and quantified by Olympus Type BX51TRF microscope (Olympus Co., Japan) and Image-Pro Plus 6.0 software (Media Cybernetics, US). Cell lipids were extracted with hexane: isopropanol at 3:2 (vol: vol). The quantities of cellular TG, TC and free cholesterol were determined by enzymatic colorimetric assays using commercial reagents (Wako Pure Chemical Industries, Japan) according to the manufacturer's protocol. The concentration of $\mathrm{CE}$ was determined by subtracting free cholesterol from TC. After lipid extraction, residual proteins were used for protein quantitative determination.

\section{Data presentation}

A transformed ratio was used to calculate fold-change of mRNA in the process of macrophages differentiation into foam cells. The fold-change of mRNA in foam cells vs. in macrophages was calculated as: $\log _{2}$ (mRNA level in foam cell/mRNA level in macrophage). We specified the value of $\log _{2}$ (mRNA level in foam cell control/mRNA level in macrophage control) as the control for all the samples in a particular study. The baseline was set to be Ratio (logarithm scale $)=0$, which means that bars with ratios greater than one (increase) pointed up, and ratios smaller than one (decrease) pointed down.

\section{Statistics}

Results were expressed as mean \pm SEM. Differences between groups were determined using one way analysis of variance (ANOVA). Dunnett's- $t$ test was used for a multiple comparison. $P<0.05$ was taken as significance.

\section{Additional files}

Additional file 1: Figure S1. Specific mRNA expressions of proteins with transcription regulated by PPARY in NEFA pre-treated macrophages and foam cells. Data represent mean \pm SEM $(n=3)$. ${ }^{*} p<0.05$ vs. the value in macrophages; ${ }^{\dagger} P<0.05$ vs. the macrophage control; ${ }^{\ddagger} P<0.05$ vs. the foam cell control.

Additional file 2: Figure S2. Specific mRNA expressions of LD-associated proteins in NEFA pre-treated macrophages and foam cells

(A.CIDE family members; B. PAT family members). Data represent mean \pm SEM $(n=3) .{ }^{*} p<0.05$ vs. the value in macrophages; ${ }^{\dagger} p<0.05$ vs. the macrophage control; ${ }^{\ddagger} p<0.05$ vs. the foam cell control. 


\section{Abbreviations}

PUFA: Polyunsaturated fatty acid; LD: Lipid droplet; NEFA: Non-esterified fatty acid; SFA: Saturated fatty acid; PA: Palmitic acid; MUFA: Monounsaturated fatty acid; OA: Oleic acid; LA: Linoleic acid; EPA: Eicosapentaenoic acid; CIDE: Cell death-inducing DFF45 like effector; PAT: Perilipin-Adipophilin-TIP47; AS: Atherosclerosis; PBMC: Peripheral blood mononuclear cell.

\section{Competing interests}

There are no conflicts of interest in this study.

\section{Authors' contributions}

YS, LJZ and HL carried out the study design, data collection and analysis, and drafted the manuscript. FFL participated in the cell-based experiments and review of the manuscript. YG and FL helped conduct the real-time PCR experiment. LNJ helped perform the isolation of ox-LDL. JY and QL were responsible for the study design, the funding, the data analysis, and the manuscript draft. All authors read and approved the final manuscript.

\section{Acknowledgments}

Authors are thankful to Dr. Bo-quan Jin (Department of Immunology, Fourth Military Medical University, Xi' an, China) for his kindly donation of THP-1 cell line and Jing-jing Zheng (Department of Neurobiology, Fourth Military Medical University, Xi' an, China) for her effort in modification of the manuscript. We also thank Li-ying Zhang, Feng Zhang, Jing Wang, Hui Wang, and Wen-peng Dong, Ting Chang, Yuan Yuan, Yu-qiao Xu, Xiang-mei Cao and Da-qing Zhao in our lab for their helpful suggestions.

\section{Author details}

${ }^{1}$ State Key Laboratory of Cancer Biology and Department of Pathology, Xijing Hospital, Fourth Military Medical University, Xi'an, China. ${ }^{2}$ Department of Clinical Laboratory, Tangdu Hospital, Fourth Military Medical University, Xi'an, China. ${ }^{3}$ Orthopedics Oncology Institute of Chinese People's Liberation Army and Department of Orthopaedics, Tangdu Hospital, Fourth Military Medical University, Xi'an, China. ${ }^{4}$ Hyperbaric Oxygen Center of Chinese People's Liberation Army, Navy General Hospital, Beijing, China.

\section{Received: 19 September 2012 Accepted: 22 July 2013}

Published: 23 July 2013

\section{References}

1. Lefterova MI, Lazar MA: New developments in adipogenesis. Trends Endocrinol Metab 2009, 20(3):107-114

2. Buers I, Hofnagel O, Ruebel A, Severs NJ, Robenek H: Lipid droplet associated proteins: an emerging role in atherogenesis. Histol Histopathol 2011, 26(5):631-642.

3. Paul A, Chan L, Bickel PE: The PAT family of lipid droplet proteins in heart and vascular cells. Curr Hypertens Rep 2008, 10(6):461-466.

4. Guo Y, Cordes KR, Farese RJ, Walther TC: Lipid droplets at a glance. J Cell Sci 2009, 122(Pt 6):749-752.

5. Chinetti G, Lestavel S, Bocher V, Remaley AT, Neve B, Torra IP, Teissier E, Minnich A, Jaye M, Duverger N, et al: PPAR-alpha and PPAR-gamma activators induce cholesterol removal from human macrophage foam cells through stimulation of the ABCA1 pathway. Nat Med 2001, 7(1):53-58.

6. Collot-Teixeira S, Martin J, McDermott-Roe C, Poston R, McGregor JL: CD36 and macrophages in atherosclerosis. Cardiovasc Res 2007, 75(3):468-477.

7. Kliewer SA, Sundseth SS, Jones SA, Brown PJ, Wisely GB, Koble CS, Devchand P, Wahli W, Willson TM, Lenhard JM, et al: Fatty acids and eicosanoids regulate gene expression through direct interactions with peroxisome proliferator-activated receptors alpha and gamma. Proc Natl Acad Sci USA 1997, 94(9):4318-4323.

8. Li H, Song Y, Li F, Zhang L, Gu Y, Zhang L, Jiang L, Dong W, Ye J, Li Q: Identification of lipid droplet-associated proteins in the formation of macrophage-derived foam cells using microarrays. Int J Mol Med 2010, 26(2):231-239.

9. Brasaemle DL, Dolios G, Shapiro L, Wang R: Proteomic analysis of proteins associated with lipid droplets of basal and lipolytically stimulated 3T3-L1 adipocytes. J Biol Chem 2004, 279(45):46835-46842.

10. Jump DB: Fatty acid regulation of gene transcription. Crit Rev Clin Lab Sci 2004, 41(1):41-78
11. Magnusson B, Gummesson A, Glad CA, Goedecke JH, Jernas M, Lystig TC, Carlsson B, Fagerberg B, Carlsson LM, Svensson PA: Cell death-inducing DFF45-like effector $C$ is reduced by caloric restriction and regulates adipocyte lipid metabolism. Metabolism 2008, 57(9):1307-1313.

12. Vallve JC, Uliaque K, Girona J, Cabre A, Ribalta J, Heras M, Masana L: Unsaturated fatty acids and their oxidation products stimulate CD36 gene expression in human macrophages. Atherosclerosis 2002, 164(1):45-56.

13. Pilz S, Scharnagl H, Tiran B, Seelhorst U, Wellnitz B, Boehm BO, Schaefer JR, Marz W: Free fatty acids are independently associated with all-cause and cardiovascular mortality in subjects with coronary artery disease. J Clin Endocrinol Metab 2006, 91(7):2542-2547.

14. Micallef MA, Garg ML: Anti-inflammatory and cardioprotective effects of $\mathrm{n}-3$ polyunsaturated fatty acids and plant sterols in hyperlipidemic individuals. Atherosclerosis 2009, 204(2):476-482.

15. Siddiqui RA, Harvey KA, Ruzmetov N, Miller SJ, Zaloga GP: n-3 fatty acids prevent whereas trans-fatty acids induce vascular inflammation and sudden cardiac death. Br J Nutr 2009, 102(12):1811-1819.

16. Lang PD, Insull WJ: Lipid droplets in atherosclerotic fatty streaks of human aorta. J Clin Invest 1970, 49(8):1479-1488.

17. Zimmermann R, Lass A, Haemmerle G, Zechner R: Fate of fat: the role of adipose triglyceride lipase in lipolysis. Biochim Biophys Acta 2009, 1791(6):494-500

18. Su YR, Blakemore JL, Zhang Y, Linton MF, Fazio S: Lentiviral transduction of apoAl into hematopoietic progenitor cells and macrophages: applications to cell therapy of atherosclerosis. Arterioscler Thromb Vasc Biol 2008, 28(8):1439-1446.

19. Kontush A, Chapman MJ: Functionally defective high-density lipoprotein: a new therapeutic target at the crossroads of dyslipidemia, inflammation, and atherosclerosis. Pharmacol Rev 2006, 58(3):342-374.

20. Pennings M, Meurs I, Ye D, Out R, Hoekstra M, Van Berkel TJ, Van Eck M: Regulation of cholesterol homeostasis in macrophages and consequences for atherosclerotic lesion development. FEBS Lett 2006, 580(23):5588-5596

21. Oram JF, Heinecke JW: ATP-binding cassette transporter A1: a cell cholesterol exporter that protects against cardiovascular disease. Physiol Rev 2005, 85(4):1343-1372

22. Kennedy MA, Barrera GC, Nakamura K, Baldan A, Tarr P, Fishbein MC, Frank J, Francone OL, Edwards PA: ABCG1 has a critical role in mediating cholesterol efflux to HDL and preventing cellular lipid accumulation. Cell Metab 2005, 1(2):121-131.

23. Gong J, Sun Z, Li P: CIDE proteins and metabolic disorders. Curr Opin Lipidol 2009, 20(2):121-126.

24. Puri V, Ranjit S, Konda S, Nicoloro SM, Straubhaar J, Chawla A, Chouinard M, Lin C, Burkart A, Corvera S, et al: Cidea is associated with lipid droplets and insulin sensitivity in humans. Proc Natl Acad Sci USA 2008, 105(22):7833-7838

25. Keller P, Petrie JT, De Rose P, Gerin I, Wright WS, Chiang SH, Nielsen AR, Fischer $C P$, Pedersen BK, MacDougald OA: Fat-specific protein 27 regulates storage of triacylglycerol. J Biol Chem 2008, 283(21):14355-14365.

26. Paul A, Chang BH, Li L, Yechoor VK, Chan L: Deficiency of adipose differentiation-related protein impairs foam cell formation and protects against atherosclerosis. Circ Res 2008, 102(12):1492-1501.

27. Ye J, Li JZ, Liu Y, Li X, Yang T, Ma X, Li Q, Yao Z, Li P: Cideb, an ER- and lipid droplet-associated protein, mediates VLDL lipidation and maturation by interacting with apolipoprotein B. Cell Metab 2009, 9(2):177-190.

28. Bickel PE, Tansey JT, Welte MA: PAT proteins, an ancient family of lipid droplet proteins that regulate cellular lipid stores. Biochim Biophys Acta 2009, 1791(6):419-440.

29. Persson J, Degerman E, Nilsson J, Lindholm MW: Perilipin and adipophilin expression in lipid loaded macrophages. Biochem Biophys Res Commun 2007, 363(4):1020-1026.

30. Wolins NE, Quaynor BK, Skinner JR, Schoenfish MJ, Tzekov A, Bickel PE: S312, Adipophilin, and TIP47 package lipid in adipocytes. J Biol Chem 2005 280(19):19146-19155.

31. Wang M, Wang D, Zhang Y, Wang X, Liu Y, Xia M: Adiponectin increases macrophages cholesterol efflux and suppresses foam cell formation in patients with type 2 diabetes mellitus. Atherosclerosis 2013, 229(1):62-70.

32. Reaven GM, Hollenbeck C, Jeng CY, Wu MS, Chen YD: Measurement of plasma glucose, free fatty acid, lactate, and insulin for $24 \mathrm{~h}$ in patients with NIDDM. Diabetes 1988, 37(8):1020-1024. 
33. de Almeida MC, Silva AC, Barral A, Barral NM: A simple method for human peripheral blood monocyte isolation. Mem Inst Oswaldo Cruz 2000 95(2):221-223

34. Mosmann T: Rapid colorimetric assay for cellular growth and survival: application to proliferation and cytotoxicity assays. J Immunol Methods 1983, 65(1-2):55-63.

35. Lowry OH, Rosebrough NJ, Farr AL, Randall RJ: Protein measurement with the Folin phenol reagent. J Biol Chem 1951, 193(1):265-275.

36. Fagot-Campagna A, Balkau B, Simon D, Warnet JM, Claude JR, Ducimetiere $P$, Eschwege $E$ : High free fatty acid concentration: an independent risk factor for hypertension in the Paris Prospective Study. Int I Epidemiol 1998, 27(5):808-813.

37. Beeharry N, Chambers JA, Green IC: Fatty acid protection from palmitic acid-induced apoptosis is lost following PI3-kinase inhibition. Apoptosis 2004, 9(5):599-607.

38. Wilcox $\mathrm{HG}$, Heimberg M: Isolation of plasma lipoproteins by zonal ultracentrifugation in the B14 and B15 titanium rotors. J Lipid Res 1970, 11(1):7-22.

39. Patsch JR, Aune KC, Gotto AJ, Morrisett JD: Isolation, chemical characterization, and biophysical properties of three different abnormal lipoproteins: LP-X1, LP-X2, and LP-X3. J Biol Chem 1977, 252(6):2113-2120

\section{doi:10.1186/1476-511X-12-111}

Cite this article as: Song et al:: Polyunsaturated fatty acid relatively decreases cholesterol content in THP-1 macrophage-derived foam cell: partly correlates with expression profile of CIDE and PAT members. Lipids in Health and Disease 2013 12:111.

\section{Submit your next manuscript to BioMed Central and take full advantage of:}

- Convenient online submission

- Thorough peer review

- No space constraints or color figure charges

- Immediate publication on acceptance

- Inclusion in PubMed, CAS, Scopus and Google Scholar

- Research which is freely available for redistribution 